\title{
Nutritient intake of young children with Prader-Willi syndrome
}

\author{
Marianne Lindmark'*, Kerstin Trygg ${ }^{2}$, Kaja Giltvedt' and \\ Svein O. Kolset ${ }^{2}$
}

'Frambu Resource Centre for Rare Disorders, Siggerud, Norway; ${ }^{2}$ Department of Nutrition, IMB, University of Oslo, Blindern, Oslo, Norway

Abstract

Background: Prader-Willi syndrome (PWS) is a rare genetic disorder resulting in obesity. The diets for young children with PWS must balance the importance of preventing development of obesity with the need to supply sufficient energy and essential nutrients.

Objective: To investigate the nutritional intake for children with PWS 2, 3, and 4 years of age and compare it with Nordic Nutritional Recommendations (NNR) and intake of healthy controls.

Design: Assessments of food intake for six children 2-4 years of age were performed twice a year. At the age of 2 and 3 years data was obtained by using food recall interviews and at 4 year of age a pre-coded food-diary was used.

Results: The energy intake for the 2-year-old children was 3.25 MJ/day (SD 0.85) and for the 3- and 4-year olds 3.62 MJ/day (SD 0.73) and 4.07 MJ/day (SD 0.39 MJ), respectively. These intakes are 61\%, 68\%, and $77 \%$ of the estimated energy requirements in NNR for healthy 2-, 3- and 4-year-old children, respectively, and $60 \%$ and $66 \%$ of the energy intakes of 2- and 4-year-old children in reference populations. The children's BMI-for-age score and length growth was within the normal range during the study period. The intake of fat was about $25 \mathrm{E} \%$ in all age groups and reduced when compared with reference populations. In $25 \%$ of the assessments the fat intake was $20 \mathrm{E} \%$ or below. The intake of iron was below recommendations in all age groups both with and without supplementation. The mean intake of vitamin D and tocopherol was below recommendations when intakes were determined excluding dietary supplementations.

Conclusions: More large-scale investigations on nutritional intake are needed to further investigate dietary challenges for this patient group.

Keywords: Prader-Willi syndrome; child; energy intake; fat; unsaturated fatty acids; micronutrients; dietetics

Received: 16 October 2009; Revised: 13 January 20 I0; Accepted: 15 February 20 I0; Published: 17 March 2010

$\mathrm{T}$ he Prader-Willi syndrome (PWS) is a complex, multisystem disorder of genetic origin due to lack of paternally active genes in chromosome 15 q11q13. The birth incidence of the condition is reported to be $1: 22,000$ to $1: 29,000$ with no gender or ethnic differences of distribution (1-3). The three different genetic mechanisms leading to PWS are deletions $(70 \%)$, maternal uniparental disomies (UPD) (28\%), and imprinting defects $(>2 \%)$ (4). The major clinical features include neonatal hypotonia and failure to thrive and childhood onset of hyperphagia that typically occurs from age between 2 and 6 years of age, which in turn, will lead to obesity in the absence of energy restrictions. Other features include short stature, hypogonadism, learning disability, developmental delay, and behavioral problems (4-6). Hypothalamic dysfunction may be responsible for many of the clinical features seen in PWS (7).
The management of PWS involves a multidisciplinary life-long approach to improve quality of life, prevent complications, and prolong life expectancy. Prevention and treatment of obesity is essential and depend on a lowenergy and well-balanced diet with rigorous supervision and restriction of food access, combined with regular meals and exercise (8).

The nutritional intakes for persons with PWS have traditionally been described as having two phases. Firstly, poor feeding and frequent failure to thrive, occurring from birth to early infancy and secondly, the onset of hyperphagia leading to obesity. A more complex progression and development with several nutritional phases during the first year has also been reported (9).

The energy requirements for children from 8 year of age and adults with PWS are found to be $20-30 \%$ reduced compared with healthy age-matched controls $(10,11)$. 
The lower energy expenditure is to a large degree explained by reduced metabolic rate and due to altered body composition with a lower muscle mass $(11,12)$. Furthermore, persons with PWS have been reported to have a more inactive lifestyle $(11,13)$. There has been less focus on the energy requirements of young children with PWS than those of older children and adults. Guidelines on energy requirements for children with PWS must therefore be used with caution. Excessive energy intake may lead to overweight, whereas inadequate energy intake may have serious consequence for the children's growth and development.

Today, many of the children with PWS are diagnosed during their first month of life due to the presence of neonatal hypotonia, which leads to genetic testing and diagnosis. Parents and caregivers will therefore at an early stage become aware of the high risk for development of obesity for their children. However, there are no established routines in Norway today involving counseling with a registered dietitian at the time of diagnosis. This leaves parents and caregivers with the challenges of preventing development of obesity combined with presenting a diet with sufficient energy and essential nutrients to ensure optimal growth and development.

To the best of our knowledge there are no systematic studies published on the actual nutritional intake in persons with PWS. This is a paradox since specific dietregimes are recommended and widely used as part of the management for this condition (8). The recommended regime includes reduced access to foods, drinks, and rigorous supervision. To deprive a person the opportunities to influence his/her own food intake raises important ethical issues. In PWS restriction of food availability and strict monitoring is considered to be in the best interest for the person(s) involved. However, this also raises the need to make sure the diet is nutritionally sufficient in all essential nutrients and in accordance with general recommendations on diets for optimal health and development. The nutritional intake for young children in growth and development is especially an important issue.

The aim of this study was to investigate the nutritional intake for young children with PWS in Norway and to compare it with Nordic Nutritional Recommendations (NNR) (14) and with healthy age-matched Norwegian children as reference population $(15,16)$. Results presented suggest that total intake of energy and fat for young children with PWS is reduced compared with agematched reference populations, and that the intake of micronutrients is low for several nutrients if dietary supplements are not used.

\section{Subjects}

The parents of seven children with PWS born in Norway from 2000 to 2002 were invited to participate in this study in 2003. The diagnoses were genetically verified by florescence in situ hybridization (FISH) chromosome test and DNA-analysis for the one child with maternal uniparental disomy (UPD). At the time of invitation the families were given both written and oral information about the study. All invited families accepted the invitation and gave written informed consent to participate. The study group constituted the total known population of children alive with PWS in Norway born in this particular period. All the children in this study were diagnosed with PWS in their first months of life. One child died early in the study period and data on six children are therefore presented here (three male and three female). The project was approved by Regional Committee for Medical and Health Research Ethics and Norwegian Social Science Data Service.

\section{Methods}

Four assessments of food intake at the age of 2 and 3 years were performed. The first, third, and fourth assessments were by food recall interview with parents and day-care personnel, either at their homes or in the day-care centers. The second assessment during this period was completed by only interviewing one of the parents via telephone. There was approximately a period of six months between the different assessments. The interviews were performed by the same person who was a registered dietitian.

The year the children reached 4 years of age, the parents recorded the food consumption by using a precoded food-diary in two registration periods separated by approximately six months, with three or four days of reporting on each occasion. The pre-coded food-diary has been developed for and used in national food surveys in Norway for 4-, 9- and 13-year-old children in the general population (17).

All the recorded data was encoded and analyzed using a food database and software systems developed at the Department of Nutrition, University of Oslo.

Medical background information was collected from the records of the local hospitals. Data on weight and height were collected from records of the local maternal and child health centers. Body mass indexes (BMI) at different ages are calculated and are presented together with BMI $Z$-scores and medical background information in Table 1.

\section{Data}

Descriptive statistics with mean intake and standard derivations was used to describe the data. The energy intakes were compared with estimated energy requirements in NNR (14) and data from healthy age-matched Norwegian children in the general population $(15,16)$. Similar the intakes of energy-yielding nutrients were compared with age-matched reference populations (15, 16) and NNR (14). The intake of micronutrients was 
Table 1. Medical background information

\begin{tabular}{|c|c|c|c|c|c|c|c|c|}
\hline & \multirow{2}{*}{$\begin{array}{c}\text { Genetic } \\
\text { mechanism }\end{array}$} & \multirow{2}{*}{$\begin{array}{l}\text { Age at start of } \\
\mathrm{GH}^{\mathrm{a}} \text { treatment }\end{array}$} & \multicolumn{2}{|c|}{2 years } & \multicolumn{2}{|c|}{3 years } & \multicolumn{2}{|c|}{4 years } \\
\hline & & & BMI & Z-score (SD) & BMI & Z-score (SD) & BMI & $Z$-score (SD) \\
\hline Child I & Deletion & 3.8 years & 17.5 & +1.13 & 17.8 & +1.40 & 17.6 & +1.27 \\
\hline Child 2 & Deletion & 4.0 years & 15.8 & -0.14 & 16.9 & +0.77 & 14.7 & -1.0 \\
\hline Child 3 & Deletion & $\begin{array}{l}\text { No treatment } \\
\text { during study period }\end{array}$ & 15.1 & -0.42 & 16.5 & +0.64 & 16.8 & +0.86 \\
\hline Child 4 & $U^{\prime b}$ & 4.0 years & 16.2 & +0.36 & 15.7 & +0.07 & 15.4 & -0.08 \\
\hline Child 5 & Deletion & 3.9 years & 15.2 & -0.33 & 16.5 & +0.29 & 15.4 & -0.16 \\
\hline Child 6 & Deletion & 4.0 years & 16.0 & +0.04 & 14.3 & -1.48 & 14.5 & -1.19 \\
\hline
\end{tabular}

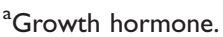

bMaternal uniparental disomy.

evaluated against NNR (14) and calculated as percentage of these recommendations. For those micronutrients where the intakes were below recommendations we also describe the intakes in the reference populations $(15,16)$. Intakes of nutrients from dietary supplements are presented separately together with information on how many children using supplementations.

\section{Results}

The mean total energy intake for the 2-year-old children with PWS was $3.25 \mathrm{MJ} /$ day, and 3.62 and $4.07 \mathrm{MJ} /$ day for the 3- and 4-year-old children, respectively. These energy intakes are $61 \%, 68 \%$, and $77 \%$ of the estimated energy requirements in NNR for the 2-, 3- and 4-year-old children, respectively, as can be seen in Table 2. For the 2- and 4-year-old children the corresponding percentages were $60 \%$ and $66 \%$, compared to age-matched children in the reference populations $(15,16)$.
The children with PWS had a mean length growth during the study period of $20.0 \mathrm{~cm}$ (SD 4.0). Five of the six children started growth hormone treatment around the age of 4 (see Table 1). Mean growth for healthy children in the same age period is $20.5 \mathrm{~cm}$ (18).

The children with PWS have in general a low intake of fat. The mean energy percent from fat was $24 \mathrm{E} \%$ for the 2-year olds, and $25 \mathrm{E} \%$ for both 3- and 4-year olds. These intakes are below the general recommendations for the population and far below those of the reference populations. The intakes of both saturated fat and monounsaturated fat are reduced when compared with intakes of the reference populations, as can be seen in Table 3, and also below recommendations in NNR (14). The mean intake of polyunsaturated fatty acids (PUFA) was approximately half of the intake of the reference populations, when compared as actual intake (g), but only $7 \%$ and $12 \%$ reduced when the intakes are compared as

Table 2. Daily intake of energy, vitamins, and minerals ${ }^{\mathrm{c}}$

\begin{tabular}{|c|c|c|c|c|c|c|}
\hline & \multicolumn{2}{|c|}{2 years $(n=6)$} & \multicolumn{2}{|c|}{3 years $(n=6)$} & \multicolumn{2}{|c|}{4 years $(n=6)$} \\
\hline & Mean $(S D)^{a}$ & NNR (\%) & Mean $(S D)^{a}$ & NNR (\%) & Mean $(S D)^{\mathrm{a}}$ & NNR (\%) \\
\hline Energy (MJ) & $3.25(0.85)$ & 61 & $3.62(0.73)$ & 68 & $4.07(0.39)$ & 77 \\
\hline Retinol $(\mu \mathrm{g})$ & $2,019(1,292)$ & 576 & I,384 (953) & 395 & $1,025(565)$ & 292 \\
\hline Vitamin D $(\mu g)$ & I5.6 (I4.5) & 208 & I5.I (6.2) & 201 & $7.2(4.5)$ & 96 \\
\hline Tocopherol (mg) & I3.2(| (I.6) & 264 & I5.I (5.4) & 302 & $9.8(3.9)$ & 195 \\
\hline Thiamin (mg) & I.2(0.5) & 200 & I.I (0.6) & 183 & $1.2(0.4)$ & 200 \\
\hline Riboflavin (mg) & $1.54(0.75)$ & 220 & $1.48(0.83)$ & 211 & $1.58(0.52)$ & 166 \\
\hline Ascorbic acid (mg) & $80(32)$ & 266 & $52(24)$ & 173 & $63(21)$ & 210 \\
\hline Calcium (mg) & $596(332)$ & 99 & $602(\mathrm{III})$ & 100 & $710(117)$ & 118 \\
\hline Iron (mg) & $6.9(3.2)$ & 86 & $6.7(3.7)$ & 84 & $7.7(3.5)$ & 96 \\
\hline Magnesium (mg) & I44 (57) & 120 & $157(35)$ & 131 & $180(36)$ & 150 \\
\hline
\end{tabular}

${ }^{\text {a }}$ Standard deviation.

bercent of Nordic Nutrition Recommendations 2004.

'Dietary supplements included. 
Table 3. Daily intake of energy-yielding nutrients

\begin{tabular}{|c|c|c|c|c|c|}
\hline & \multicolumn{2}{|c|}{2 years $(n=6)$} & \multirow{2}{*}{$\begin{array}{c}3 \text { years }(n=6) \\
\text { Mean }(S D)^{\mathrm{a}}\end{array}$} & \multicolumn{2}{|c|}{4 years $(n=6)$} \\
\hline & Mean $(S D)^{a}$ & $\mathrm{RP}(\mathrm{SD})^{\mathrm{a}, \mathrm{b}}$ & & Mean $(S D)^{a}$ & $\mathrm{RP}(\mathrm{SD})^{\mathrm{a}, \mathrm{c}}$ \\
\hline Fat E\% & $23.8(7.3)$ & $33.3(5.1)$ & $24.8(5.1)$ & $24.5(4.3)$ & $32.5(4.8)$ \\
\hline Saturated fat E\% & $7.6(2.8)$ & $14.2(2.7)$ & $8.3(2.5)$ & $9.3(2.3)$ & $14.2(2.5)$ \\
\hline Monounsaturated fat E\% & $7.9(3.3)$ & $10.4(1.8)$ & $8.1(1.8)$ & $8.0(1.8)$ & $9.9(1.7)$ \\
\hline Polyunsaturated fat E\% & $5.6(2.4)$ & $5.7(1.9)$ & $5.4(1.9)$ & $5.0(1.4)$ & $6.0(1.7)$ \\
\hline Protein E\% & $16.6(3.7)$ & I3.4 (I.8) & I8.I (2.9) & $20.3(2.1)$ & I4.I (2.5) \\
\hline Carbohydrate E\% & $57.3(7.1)$ & $53.3(5.6)$ & $56.8(6.6)$ & $55.2(5.8)$ & $53.5(5.5)$ \\
\hline Sugar E\% & $4.3(5.6)$ & II.7 (5.8) & $2.6(2.0)$ & $5.0(4.9)$ & I5.2 (5.5) \\
\hline
\end{tabular}

${ }^{\text {aS }}$ tandard deviation.

bMean intake in Reference population (I5).

'Mean intake in Reference population (16).

percent of total energy intake $(15,16)$. The mean intake of PUFA was within recommendations in NNR (14).

In $25 \%$ of the assessments the intake of fat was $20 \mathrm{E} \%$ or less of the total energy intake. In most of these assessments the intakes of PUFA were below recommendations (14).

The intake of protein was higher when expressed as percent of total energy intake in the PWS population compared with the reference populations for both the 2and 4-year olds. However, when expressed as gram protein per $\mathrm{kg}$ the intake was $3.0 \mathrm{~g} / \mathrm{kg}$ for the 2 -yearold children with PWS and $3.7 \mathrm{~g} / \mathrm{kg}$ in the reference population (15). For the 3-year olds the intakes in the PWS group was $3.1 \mathrm{~g} / \mathrm{kg}$, and for the 4-year-old children $3.2 \mathrm{~g} / \mathrm{kg}$ in the PWS group and $2.9 \mathrm{~g} / \mathrm{kg}$ in the reference population (16). The intake of protein in the PWS groups was within the recommended level of intake in NNR on all assessments (14).

The intake of carbohydrates expressed as percent of total energy intake was similar both in children with PWS at different age and the reference populations, as can be seen in Table 3. The intakes of carbohydrates for the children with PWS were within the NNR recommendations (14). However, the mean intakes of sugar for the children with PWS were considerably lower than intakes in the reference populations $(15,16)$, and within the recommendations (14).

In general, the diets contained enough water-soluble vitamins even without supplementations. However, the mean intake of vitamin D was only $26 \%, 38 \%$, and $32 \%$ of NNR for the 2-, 3-, and 4-year olds, respectively, when excluding the dietary supplements. Similarly the intake of tocopherol was $47 \%, 45 \%$, and $57 \%$ of NNR for the 2-, 3-, and 4-year olds, respectively. However, it is worth noting that the intake of vitamin $\mathrm{D}$ in the reference population was only $35 \%$ of NNR in both the 2- and 4-year-old children when calculated without supplementations, whereas the intake of tocopherol was $84 \%$ and $90 \%$ of
NNR for the 2- and 4-year-old children in the reference population $(15,16)$.

The mean intake of iron in the PWS group was found to be somewhat below NNR in all age groups (84-96\%), as can be seen in Table 2. Similar levels of intakes have also been reported in the reference population with an intake at $89 \%$ and $83 \%$ of NNR in the 2- and 4-year-old children $(15,16)$.

The mean intake of calcium reached the recommended level in the PWS children, but the intakes differed to a large extent within the 2- and 3-year-old groups. Three of six children at 2 years of age and two of those 3 years of age did not reach the recommended level of intake. The children with low intake of calcium drank milk only occasionally and mainly used dairy products as part of food preparations. The mean intake of calcium in the reference population was $129 \%$ and $113 \%$ of NNR for the 2 - and 4-year-old children, respectively $(15,16)$.

The use of dietary supplementation and how this affects the mean intake of energy, vitamins, and minerals in the different age-groups are presented in Table 4. The children with PWS used supplementation with either cod liver oil, multivitamins, multivitamin-minerals, or a combination of these. Most children used one dietary supplement but some used a combination of two. At the age of 2 years, one child used a combination of cod liver oil and multivitamin-mineral. At the age of 3 years, none combined several supplements. Finally, at 4 years of age one child used a combination of cod liver oil and multivitamin-minerals, whereas one child used cod liver oil and multivitamins. Cod liver oil increases the intake of the fat-soluble vitamins as well as PUFA.

\section{Discussion}

This study on the nutritional intake for children with PWS involves a small number of participants. Seven children were recruited for the study. Based on data on birth rate in Norway for 2000-2002 (19) divided with the 
Table 4. Daily intake of energy, vitamins, and minerals from dietary supplements ${ }^{\mathrm{a}}$

\begin{tabular}{|c|c|c|c|c|c|c|}
\hline & \multicolumn{2}{|c|}{2 years } & \multicolumn{2}{|c|}{3 years } & \multicolumn{2}{|c|}{4 years } \\
\hline & Mean & $N^{\mathrm{b}}$ & Mean & $N^{\mathrm{b}}$ & Mean & $N^{\mathrm{b}}$ \\
\hline Energy (MJ) & 0.02 & 2 & 0.14 & 3 & 0.08 & 2 \\
\hline Retinol $(\mu \mathrm{g})$ & $|, 57|$ & 5 & 980 & 5 & 359 & 5 \\
\hline Vitamin D $(\mu \mathrm{g})$ & 13.6 & 5 & 12.2 & 5 & 4.8 & 4 \\
\hline Tocopherol (mg) & 10.8 & 5 & 12.8 & 5 & 6.9 & 4 \\
\hline Thiamin (mg) & 0.55 & 3 & 0.37 & 2 & 0.32 & 3 \\
\hline Riboflavin (mg) & 0.63 & 3 & 0.44 & 2 & 0.3 & 3 \\
\hline Ascorbic acid (mg) & 22 & 3 & 16 & 2 & 12 & 3 \\
\hline Calcium (mg) & 0 & 0 & 0 & 0 & 0 & 0 \\
\hline Iron (mg) & 0 & 0 & 0.6 & I & 1.7 & 1 \\
\hline Magnesium (mg) & 13 & I & 13 & 1 & 0 & 0 \\
\hline
\end{tabular}

${ }^{a}$ Type of dietary supplements used: Cod liver oil, multivitamin, and multivitamin minerals.

${ }^{b}$ Number of children using dietary supplement of the nutrient.

number of children with PWS recruited for this study give an incidence of 1:24,447. Given the reported incidence for PWS we conclude that our study most likely include all children alive with PWS born in Norway from 2000 to 2002.

Self-reported methods as those used in this study may be subject to bias and underestimations of energy intake have been reported $(17,20)$. We collected data twice a year to limit the difference in dietary intake due to seasonal differences. The pre-coded food-diary used for the 4-year-old children has been validated and shown to give a lower intake of energy, fat, and sugar compared to 24-h recall (21). Furthermore, compared to energy expenditure data the underreporting with this method was $18 \%(22)$.

In this study we show that the children with PWS have approximately $20-40 \%$ reduced energy intake compared to NNR and surveys among other Norwegian children their age (14). Children with PWS are expected to have a reduced requirement for energy, even though this has not been a subject of proper investigations and the literature mostly refers to clinical experiences (9). The literature suggested that the energy intakes are restricted to prevent obesity, but there is some disagreement at what age the reduced energy requirements starts and the extent of energy restrictions required (9). Uncertainties on energy requirements for small children with PWS and the widespread use of growth hormone treatment seen today, emphasize the need for more investigations on energy requirements.

We found no support for reduced growth due to reduced energy intake among the children in our study. We also found normal BMI-for-age throughout the study period. These findings support the notion that energy intake was appropriate for the children studied. In another study a fat-reduced and carbohydrate modified diet providing $10 \mathrm{kcal} / \mathrm{cm}(42 \mathrm{~kJ} / \mathrm{cm})$ of height starting at the second year of life, resulted in shorter stature when compared with a control group of persons with PWS diagnosed at a later stage in life (23).

Our data suggest that some parents and caregivers of children with PWS restrict the intake of fat too much. Very low intakes of fat (e.g. below $20 \mathrm{E} \%$ of total energy intake) increase the risk for inadequate intake of PUFA. This may have negative consequences for brain and nervous system development (24). This finding indicates that parents of children with PWS may need professional assistance on food selection. The guidance should include information on foods with appropriate fat content and how much fat the children need.

High intakes of sugar are one of the nutritional challenges for children in Norway (25). More than 50\% of the children 2 years of age (15), and $80 \%$ of children 4 years of age (16) in the general population consume more sugar than recommended. The intake of sugar in the PWS population was considerably below the intakes of the reference populations. The difference in intake of sugars is mainly explained by the difference in consumption of soft drinks.

The data presented also show that children with PWS have low intake of several essential nutrients. This is mainly due to the reduced intake of energy. Our findings suggest that children with PWS may need dietary supplementation of vitamin D and tocopherol, and the minerals iron and calcium. Calcium could also be increased by increasing the diet contents of low-fat dairy products. Due to the increased reported risk for osteoporosis supplementation of vitamin D and calcium are recommended for individuals with PWS (26). Many of the children in our study used dietary supplementation, but none used calcium supplementation even though this is a clear recommendation for the patient group.

Parents and caregivers of young children with PWS should be offered evaluations of the dietary intake by a registered dietitian to ensure optimal growth and development. Attention should be given to the intake of energy, fat, vitamin D, tocopherol, iron, and calcium. More large-scale investigations on the dietary intake of people with PWS should be performed.

\section{Acknowledgements}

The authors wish to acknowledge all the families who participated in this study.

\section{Conflict of interest and funding}

The author has not received any funding or benefits from industry to conduct this study. 


\section{References}

1. Whittington JE, Holland AJ, Webb T, Butler J, Clarke D, Boer $\mathrm{H}$. Population prevalence and estimated birth incidence and mortality rate for people with Prader-Willi syndrome in one UK Health Region. J Med Genet 2001; 38: 792-8.

2. Vogels A, Van Den Ende J, Keymolen K, Mortier G, Devriendt $\mathrm{K}$, Legius E, et al. Minimum Prevalence, birth incidence and cause of death for Prader-Willi syndrome in Flanders. Eur J Hum Genet 2004; 12: 238-40.

3. Thomson AK, Glasson EJ, Bittles AH. Long-term populationbased clinical and morbidity review of Prader-Willi syndrome in Western Australia. J Intellect Disabil Res 2006; 50: 69-78.

4. Cassidy SB. Prader Willi syndrome. J Med Genet 1997; 34: 917-23.

5. Holm VA, Cassidy SB, Butler MG, Hanchett JM, Greenswag LR, Whitman BY, et al. Prader Willi syndrome: consensus diagnostic criteria. Pediatrics 1993; 91: 398-402.

6. Gunay-Aygun M, Schwartz S, Heeger S, O'Riordan MA, Cassidy SB. The changing purpose of Prader-Willi syndrome clinical diagnostic criteria and proposed revised criteria. Pediatrics 2001. Available from: http://www.pediatrics.org/cgi/content/ full/108/5/e92 [cited 25 May 2009].

7. Swaab DF. Prader-Willi syndrome and the hypothalamus. Acta Paediatrica Suppl 1997; 423: 50-4.

8. Goldstone AP, Holland AJ, Hauffa BP, Hokken-Koelega AC, Tauber M. Recommendations for the diagnosis and management of Prader-Willi syndrome. J Clin Endocrinol Metab 2008; 93: 4183-97.

9. McCune H, Driscoll DJ. Prader-Willi syndrome. In: Ekvall SW, Ekvall VF, eds. Pediatric nutrition in chronic diseases and developmental disorders, 2nd ed., New York: Oxford University press; 2005, pp. 128-32.

10. Schoeller DA, Levitsky LL, Bandini LG, Dietz WW, Walcak A. Energy expenditure and body composition in Prader-Willi syndrome. Metabolism 1988; 37: 115-20.

11. Butler MG, Theodoro MF, Bittel DC, Donnelly JE. Energy expenditure and physical activity in Prader-Willi syndrome: comparison with obese subjects. Am J Med Genet 2007; 143: 449-59.

12. VanMil EA, Westerterp KR, Gerver WJ, Curfs LM, ScharanderStumpel CT, Kester AD, et al. Energy expenditure at rest and during sleep in children with Prader-Willi syndrome is explained by body composition. Am J Clin Nutr 2000; 71: 752-6.

13. Davies PS, Joughin C. Using stable isotopes to assess reduced physical activity of individuals with Prader-Willi syndrome. Am J Ment Retard 1993; 98: 349-53.

14. Nordic Council of Ministers, eds. Nordic nutrition recommendations 2004: integrating nutrition and physical activity. Copenhagen: Scanprint Århus; 2004.

15. Lande B, Andersen LF. Kosthold blant 2-åringer: Landsomfattende kostholdsundersøkelse - Småbarnskost [Dietary intake among 2 year olds: a national foodsurvey - Toddlersdiet] Oslo: Sosial og helsedirektoratet; 2005, report: IS-1299 [in Norwegian].
16. Pollestad ML, Øverby NC, Andresen LF. Kosthold blant 4åringer: Landsomfattende kostholdsundersøkelse UNGKOST2000 [Dietary intake among 4 year olds: a national foodsurvey, Youthsdiet-2000] Oslo: Sosial og helsedirektoratet; 2002, report: IS-1067 [in Norwegian].

17. Andersen LF, Tomten H, Haggarty P, Lovo A, Hustvedt BE. Validation of intake from a food frequency questionnaire: a doubly labelled water study. European J Clin Nutr 2003; 57: 279-84.

18. Knudtzon J, Waaler PE, Skjaerven R, Solberg LK, Steen J. New Norwegian percentage charts for height, weight and head circumference for age groups $0-17$ years. Tidsskr Nor Laegeforen 1998; 108: 2125-35.

19. Statistics Norway. Available from: http://www.ssb.no/english/ subjects/02/02/10/fodte_en/tab-2009-04-02-01-en.html; 2009. [cited 1 September 2009].

20. Kroke A, Klipstein-Grobusch K, Voss S, Moseneder J, Thielecke F, Noack R, et al. Validation of a self-administrated food-frequency questionnaire administered in the European prospective investigation into cancer and nutrition (EPIC) study: comparison of energy, protein, and macronutrient intakes estimated with the doubly labeled water, urinary nitrogen, and repeated 24-h dietary recall methods. Am J Clin Nutr 1999; 70: $439-47$.

21. Hjartaker H, Andersen LF, Lund E. Comparison of diet measures from a food-frequency questionnaire with measures from repeated 24-hour dietary recalls. The Norwegian woman and cancer study. Public Health Nutr 2007; 10: 1094-103.

22. Lillegaard IT, Andersen LF. Validation of a pre-coded food diary with energy expenditure, comparison of underreports $\mathrm{v}$. acceptable reporters. Br J Nutr 2005; 94: 998-1003.

23. Schmidt H, Pozza SB, Bonfig W, Schwarz HP, Dukoupil K. Successful early dietary intervention avoids obesity in patients with Prader-Willi syndrome: a ten-year follow-up. J Pediatr Endocrinol 2008; 21: 651-5.

24. Belkind-Gerson J, Carreón-Rodríguez A, Contreras-Ochoa CO, Estrada-Mondaca S, Parra-Cabrera MS. Fatty acids and neurodevelopment. J Pediatr Gastroentrol Nutr 2008; 47: 57-9.

25. Overby NC, Lillegaard IT, Andersen LF. Hight intake of added sugar among Norwegian children and adolescents. Public Health Nutr 2004; 7: 285-93.

26. Cassidy SB, Schwartz S. Prader-Willi syndrome. Genereviews 2009. Available from: http://www.ncbi.nlm.nih.gov/bookshelf/ br.fcgi?book=gene\&part=pws [cited 4 January 2010].

\footnotetext{
* Marianne Lindmark

Frambu Resource Center for Rare Disorders

Sandbakkveien 18

I 404 Siggerud, Norway

Tel: +4764856047

Fax: +4764856099

Email: marianne.lindmark@frambu.no
} 